Mens

Revue d'histoire intellectuelle et culturelle

mens

Karim Larose et Frédéric Rondeau (dir.). La contre-culture au

Québec, Montréal, Les Presses de l'Université de Montréal, 2016, 524 p.

\title{
Alex Giroux
}

Volume 17, numéro 1-2, automne 2016, printemps 2017

URI : https://id.erudit.org/iderudit/1050793ar

DOI : https://doi.org/10.7202/1050793ar

Aller au sommaire du numéro

Éditeur(s)

Centre de recherche en civilisation canadienne-française

ISSN

1492-8647 (imprimé)

1927-9299 (numérique)

Découvrir la revue

Citer ce compte rendu

Giroux, A. (2016). Compte rendu de [Karim Larose et Frédéric Rondeau (dir.).

La contre-culture au Québec, Montréal, Les Presses de l'Université de Montréal,

2016, 524 p.] Mens, 17(1-2), 176-181. https://doi.org/10.7202/1050793ar d'utilisation que vous pouvez consulter en ligne.

https://apropos.erudit.org/fr/usagers/politique-dutilisation/ 
aurait ajouté un intérêt à la lecture de l'ouvrage, surtout pour ceux qui connaissent moins l'histoire du livre et des bibliothèques au Québec.

Avec une remarquable bibliographie de 22 pages, incluant des sources et des études, et un index fort utile, l'auteur fait plus que rassembler la documentation sur le sujet, il y ajoute de nouvelles informations qui mettent à jour le connu et enrichissent l'historiographie des bibliothèques. Dans Le Devoir du 6 décembre 2016, François Séguin déclarait s'honorer de son titre de bibliothécaire. La contribution qu'il offre à nos connaissances sur l'histoire des bibliothèques contribue assurément à donner à ce titre toute la noblesse qui lui revient.

- Gilles Gallichan Bibliothécaire et historien

\section{Karim Larose et Frédéric Rondeau (dir.). La contre-culture au Québec, Montréal, Les Presses de l'Université de Mon- tréal, 2016, 524 p.}

Avec ce premier collectif scientifique sur la contre-culture au Québec, on concrétise l'existence d'un champ de recherche multidisciplinaire. Les quinze chapitres couvrent large; les auteurs se sont intéressés à la musique, au cinéma, au théâtre, à la poésie, à la bande dessinée, aux arts visuels et aux discours comparés avec d'autres militantismes, en l'occurrence, féministe et homosexuel. On concrétise ainsi un effort de diversification des objets, ce qui permet de mieux saisir l'ampleur et la complexité d'un mouvement dont on avait surtout retracé les racines philosophiques et historiques puis qu'on avait analysé sous l'angle politique ${ }^{1}$. Plusieurs auteurs proposent un retour

1 Theodore Roszak, Vers une contre-culture : réflexions sur la société technocratique et l'opposition de la jeunesse, traduit par Claude Elsen, Paris, Stock, 1970; Gaétan Rochon, Politique et contre-culture : essai d'analyse interprétative, LaSalle, Hurtubise HMH, 1979; Jules Duchastel, «La contre-culture, une idéologie de l'apolitisme », dans Association canadienne des sociologues et anthropologues de langue française, La transformation du pouvoir au Québec : actes du colloque de l'ACSALF, Laval, Éditions coopératives Albert Saint-Martin, 1979, p. 253-264. 
sur les premières études portant sur le mouvement, posées en jalons du champ de recherche, à la lumière de nouvelles conclusions et de nouveaux questionnements.

Le collectif concrétise un objectif important : clarifier l'abrasif discours contre-culturel jusqu'alors marginalisé et affirmer sa pertinence sur le plan historique et historiographique. Il y arrive par l'analyse complète et profonde d'un nombre limité d'œuvres et la mise en lumière de la globalité du raisonnement de quelques acteurs clés de la mouvance. Les textes abordent les œuvres d'auteurs-es Denis Vanier, Josée Yvon, Patrick Straram, Louis Geoffroy, Paul Chamberland, Raôul Duguay, Jean Basile, Victor-Lévy Beaulieu, Pierre Léger-, de l'artiste visuel Jean-Paul Mousseau, des musiciens du Quatuor de jazz libre du Québec et de ceux fréquentant le centre d'essai Le Conventum, des cinéastes Pierre Harel, Serge et Jean Gagné, des bédéistes Pierre Dupras, André Philibert et ceux du groupe Chiendent, des troupes de théâtre Euh!, du Grand Cirque Ordinaire et du Théâtre du Même Nom. Dans son ensemble, le volume donne à voir une formidable diversité artistique et une polyvalence des acteurs de la contre-culture, lesquelles rendent ce livre presque incontournable pour quiconque travaillera sur les transformations de la culture et de la société dans les années 1960 et 1970 au Québec.

L'ouvrage réussit donc à circonscrire la contre-culture comme objet de recherche en réunissant des chercheurs de tous les milieux qui travaillent selon des approches et des cadres théoriques divers. Il ne remplace pas, cependant, une synthèse comme celle d'Andrée Fortin et Jean-Philippe Warren ${ }^{2}$, puisqu'il n'est pas traversé par un fil conducteur liant l'ensemble des manifestations du mouvement. La redéfinition du concept de contre-culture s'en retrouve alors morcelée, impression accentuée par l'absence de conclusion. Pour ces raisons, le livre semble bien peu correspondre à un ouvrage d'introduction à la contre-culture, mais il peut s'adresser autant aux

2 Pratiques et discours de la contreculture au Québec, Québec, Éditions du Septentrion, 2015. 
lecteurs voulant approfondir leur compréhension de l'objet qu'aux curieux intéressés par une discipline artistique ou une approche particulière. Un index, une chronologie et une bibliographie très complète renforcent sa fonction de tremplin pour de plus amples recherches dans le domaine. Il est bien sûr possible d'y repérer quelques lignes de force qui s'insèrent dans un nouveau récit historique de la contre-culture québécoise.

Une des forces de l'ouvrage est de montrer comment la « mouvance " contre-culturelle a investi la vie artistique et sociale de façon complètement renouvelée, grâce à une liberté créatrice sans bornes, dont l'improvisation collective est un aspect crucial. Plus aucun champ de création n'est désormais à l'abri d'un renouvellement complet des pratiques et des cadres : le Quatuor de jazz libre du Québec et son improvisation destructrice et militante dont traite Éric Fillion; la musique contemporaine underground des futurs " actualistes ", dont le réseau est retracé par Marie-Thérèse Lefebvre; les troupes de théâtre antihiérarchiques, abolissant les décors et mélangeant le cirque à la musique et à l'improvisation, analysées par Jean-Marc Larrue; Pierre Harel et ses films volontairement décousus et grotesques, dont les scénarios minimalistes laissent une grande place à la créativité de l'acteur, selon Sacha Lebel et Germain Lacasse. Alors que Robert Schwartzwald montre comment certains membres du Front de libération homosexuel (FLH) repensent le vivre-ensemble de la collectivité, Marie-Andrée Bergeron revisite le discours de la revue Mainmise, qui propose une libération de la société patriarcale, où les relations amoureuses sont tributaires de l'égalité des sexes et où de nouvelles formes d'union sont explorées, par exemple le mariage de groupe. Bref, rien ne semble impossible, et c'est pourquoi la contre-culture est un phénomène "protéiforme », selon l'expression de Simon-Pierre Labelle-Hogue, et tend vers la multiplicité des démarches.

Dans cette effervescence exploratoire, plusieurs démarches témoignent d'une volonté de partager une puissante expérience avec leur public. L'art doit pouvoir solliciter le potentiel artistique de tout un chacun par la participation à l'œuvre et à la prise de risque, selon 
certains acteurs. En démocratisant la création, on pense libérer les consciences du plus grand nombre. Dans le chapitre cinq, de MarcAndré Robert, on voit comment le collage cinématographique Une semaine dans la vie de camarades des frères Gagné juxtapose des " travailleurs culturels » de chaque région du Québec à des " contreculturistes " rassemblés à Montréal pour la semaine de la contre-culture en 1975. On souhaite alors mettre sur un pied d'égalité le travail culturel des uns et des autres dans une logique de réappropriation de la culture à l'encontre des pouvoirs qui l'instrumentalisent. Même son de cloche chez Jean-Paul Mousseau, issu du mouvement des Automatistes; Anithe de Carvalho nous montre comment il transforme une discothèque en une œuvre d'art qui favorise l'expression et le jeu des clients. Sébastien Dulude souligne habilement comment Denis Vanier souhaite provoquer une réaction chez son lecteur en le forçant à se rapprocher d'images pornographiques afin de déchiffrer les caractères imprimés sur ces mêmes images. Par ces opérations qui redéfinissent leur rapport au public, les artistes déconstruisent les espaces traditionnels de la consommation culturelle tels que la scène, le musée ou le livre de poésie.

On ne peut que constater la puissante charge de la contre-culture contre un lourd héritage social et culturel, la normalisation et le conformisme institués par les élites traditionnelles sur les membres de la société. En musique populaire, objet d'étude de Jean-Pierre Sirois-Trahan, le mouvement Ti-Pop a tôt fait de désacraliser les différents symboles, rituels et vocables associés à l'autorité cléricale dans l'imaginaire. Au Théâtre Euh! et au Grand Cirque Ordinaire, les autorités morales de la cellule familiale et de la politique traditionnelle sont discréditées par leurs représentations sous forme de caricatures écrasantes. Dans le film Bulldozer, Pierre Harel obtient un effet similaire par le grotesque, en montrant une famille complètement dysfonctionnelle et miséreuse. La critique y a vu la misère du peuple tout entier. Valérie Mailhot, grâce à un cadre théorique foucaldien, voit la poète Josée Yvon se révolter contre les pouvoirs normatifs sur le plan des identités et des comportements sexuels. 
Cette révolte s'exprime par un langage cru et vulgaire, une sexualité débridée et l'usage de drogues. Une volonté de choquer le bien-pensant traverse souvent les démarches contre-culturelles, opérant des « formes de mises à distance des pouvoirs normatifs ".

Les différents auteurs ont aussi réfléchi à l'apolitisme de la contreculture, formulé par Jules Duchastel en 1979. L'apparente contradiction entre cet apolitisme et les revendications indépendantistes font l'objet de discussions dans quelques textes. La libération de la collectivité québécoise facilite la libération des consciences individuelles pour le Jazz libre, les frères Gagné ou le bédéiste Pierre Dupras, dont nous entretient Camille St-Cerny Gosselin. Pour Victor-Lévy Beaulieu, dont le discours a été analysé par Frédéric Rondeau, ou pour les artisans de l'Osstidcho, devenir authentiquement Québécois, c'est nommer la colonisation d'un peuple pour mieux renaître comme individus libres. Au Front de libération homosexuel aussi, un certain militantisme contre la discrimination côtoie des idéaux communautaires et de libération individuelle. Pour la majorité des auteurs, il faut cependant voir l'engagement politique des acteurs de la contreculture au sens large. Ainsi, la résistance face à la récupération de plusieurs auteurs ou la charge d'Yvon contre « les discours organisés en lieux de pouvoir " en sont des exemples.

Au-delà de ces éléments de définition partagés par les auteurs, chacun a décortiqué de manière fine et précise des thèmes nouveaux et d'autres plus récurrents de la contre-culture. Par exemple, l'exploration de la sexualité dans quatre chapitres différents apporte un éclairage multidirectionnel : d'une part, Bergeron souligne la distance, voire l'ignorance de certains auteurs de Mainmise face aux analyses féministes, alors que l'aspect spirituel de la sexualité est exploré différemment selon les poètes Straram et Geoffroy (?), étudiés par Labelle-Hogue. Le premier renaît dans l'acte sexuel alors que le second l'associe au voyage dans un autre état de conscience après une mort symbolique. L'étude de Josée Yvon, par Mailhot, montre avec grande habileté comment la vitalité et l'exhibition des désirs deviennent une offensive aux identités sexuées normatives. 
Parmi les trois chapitres portant sur la musique, celui de SiroisTrahan couvre un éventail d'artistes extrêmement vaste, équivalent à un survol de l'évolution du rock au Québec. Par son côté encyclopédique, ce texte synthèse évacue toute analyse de fond des questions qu'il soulève sur la critique sociale et culturelle des artistes évoqués, ainsi que sur les conditions matérielles et sociales de l'émergence et de la propagation de la contre-culture musicale auprès des adeptes. Cependant, les études sont bien documentées en ce qui concerne les musiques free jazz et underground, respectivement dans les textes de Fillion et Lefebvre.

L'ouvrage dans son ensemble est hautement instructif et agréable à lire. L'objectif de donner corps et appui à un concept, celui de la contre-culture, faisant l'objet de clichés tenaces et de nostalgie confondante, est grandement réussi. La lecture de chacun des chapitres apporte une lumière sur la période qui est enrichie de noms de personnes, de groupes, de lieux et d'événements qui ne sombreront plus jamais dans l'oubli.

- Alex Giroux

Titulaire d'une maîtrise en histoire Université du Québec à Montréal

\section{Matthew Hayday et Raymond B. Blake (dir.). Celebrating Canada, t. 1 : Holidays, National Days, and the Crafting of Identities, Toronto, University of Toronto Press, 2016, $450 \mathrm{p}$.}

Les célébrations commémoratives sont des expressions symboliques du pouvoir religieux ou civil. Elles le légitiment de manière cyclique et codée, contribuant à la formation d'identités sociales. Pour la science historique, elles sont révélatrices des intentions et des stratégies des pouvoirs qui les orchestrent, ainsi que de leur influence sur le public. Coïncidant avec le $150^{\mathrm{e}}$ anniversaire de la fédération, l'ouvrage collectif dirigé par Matthew Hayday et Raymond Blake offre un regard opportun sur la commémoration au Canada. Les 